\title{
JUEZ Y CONSTITUCIÓN
}

M. ${ }^{a}$ LUISA BALAGUER CALLEJÓN

Catedrática de Derecho Constitucional

Universidad de Málaga 


\section{SUMARIO}

INTRODUCCIÓN. 1. El CONCEPTO DE JUEZ CONSTITUCIONAL. 2. LA EVOLUCIÓN hISTÓRICA DE LA FUNCIÓN JUDICIAL EN EL ORDENAMIENTO JURIDICO ESPAÑOL. a) La regulación en la LOPJ de 1870. b) La Regulación actual: El poder judicial en la Constitución española y en la Ley Orgánica 6/85, de 1 de julio del Poder Judicial. 3. LA FUNCIÓN JUDICIAL EN EL ORDENAMIENTO JURÍDICO ESPAÑOL VIGENTE. a) La aplicación del derecho y el sistema de fuentes. b) La actividad interpretativa del juez en la aplicación del derecho. c) La relación del juez con otros órganos constitucionales y jurisdiccionales. ConcluSIONES. BIBLIOGRAFIA. 


\title{
JUEZ Y CONSTITUCIÓN
}

POR

\author{
M. ${ }^{a}$ LUISA BALAGUER CALLEJÓN
}

Catedrática de Derecho Constitucional

Universidad de Málaga

\section{INTRODUCCIÓN}

La Constitución española ha supuesto una transformación importante en la función judicial y en el status del juez. Esta transformación obedece a la distinta consideración que la Constitución establece del comportamiento de los poderes públicos en un Estado Social y Democrático de Derecho, (art. 9, 2 CE), en relación con el Estado totalitario que caracterizaba al régimen anterior.

El reconocimiento del poder judicial como un poder del Estado, independiente del ejecutivo, inamovible, responsable y sometido únicamente al imperio de la ley, (art. $117 \mathrm{CE}$ ), junto a la naturaleza normativa de la Constitución, crea las condiciones de un nuevo poder judicial, que se integra en el conjunto de los poderes del Estado, asumiendo los valores y los principios constitucionales en el desempeño de su función jurisdiccional.

Este poder judicial reconocido en la Constitución, permanece en el modelo continental de raíz francesa, que adscribe al poder judicial una función aplicativa de la ley, ausente de creación, y que no detenta orgánicamente un poder de encarnación física, sino solamente un poder puntual en la aplicación del derecho, en tanto en cuanto ejerce la función jurisdiccional. La difusión de este poder en todos y cada uno 
de los jueces, y la limitación de su órgano de gobierno, el Consejo General del Poder Judicial, a funciones de ésta naturaleza, hace invisible un poder que interfiere decisiones importantes de los demás poderes, y que determina gran parte de las decisiones políticas y legislativas del Estado'.

Nuestra ponencia intenta dar una visión crítica de las consecuencias $y$ disfuncionalidades derivadas de la posición constitucional del juez, y la aportación de algunos puntos de vista que podrían orientar algunas soluciones a estos problemas.

Cuando se habla del juez constitucional se tiene la tendencia a reducir ese concepto a los jueces que componen el Tribunal Constitucional. Sin embargo, el juez constitucional debe entenderse en el sentido de que los jueces, todos los jueces, al advenimiento de la Constitución, han de adaptar su función jurisdiccional a los nuevos principios constitucionales. Se dice que el juez, todo juez, es constitucional en el sentido de adecuar el juez a la Constitución, y hay en ese término, ujuez constitucional", un voluntarismo en que los jueces se aproximen a la Constitución ${ }^{2}$.

Juez constitucional es por tanto todo juez. $Y$ con este término se indica la necesidad de que los jueces han de resolver de conformidad con la Constitución.

¿Qué innova la Constitución respecto de la figura del juez, que pueda justificar un antes y después de la Constitución en el comportamiento del juez?. Un juez es un funcionario del Estado por oposición que, investido constitucionalmente de poder, dicta una resolución de un litigio entre partes. Esta resolución es usualmente como término, una sentencia, que pone fín al procedimiento en la instancia. Y en la fundamentación jurídica de esta sentencia, el juez expresa su posición respecto del petitum, las normas en que se basa la pretensión y la oposición, y la valoración de la prueba practicada. Y esto lo hace además, de forma enumerada y articulada, mediante una distinción entre los hechos declarados probados, que son solamente datos, y la fundamenta-

1 M. GeRPE ha llamado la atención acerca del modelo de poder en la función jurisdiccional de nuestro estado constitucional. Al no haber unidad orgánica en el poder judicial, entendida esta como referencia a una encarnación física del poder judicial en una institución concreta, el poder judicial se difumina y no hay un referente claro de ese poder. M. Gerpe.- "La división de poderes: el poder judicial". A. Monreal edit. BARCELONA. 1997.

2 P. Pérez Tremps. "Tribunal Constitucional y poder judicial». CEC. MADRID. 1985. pág. 190. 
ción jurídica de la sentencia. Es en esta segunda parte donde se presentan los argumentos que sirven de base al fallo. Estos argumentos tienen dos distintos niveles de importancia, de una parte las consideraciones $u$ "abiter dicta", $y$ de otra parte las razones o "ratio decidendi», por las que el juez llega a las consecuencias jurídicas.

$Y$ es estos momentos del proceso, donde adquiere trascendencia la actividad del juez, en los que se deja ver con mayor intensidad, el cambio sustancial que la Constitución ha impuesto en la función judicial.

Frente a la visión del juez distante de la sociedad, indiferente a los valores sociales, y sometido a la estricta legalidad en la aplicación del Derecho, la Constitución favorece y potencia una función judicial comprometida con los valores $y$ principios constitucionales, que lleva implícito el reconocimiento, antes ausente, de que el juez está integrado en un sistema social de valores, de los que participa y que reproduce en el dictado de sus resoluciones ${ }^{3}$.

\section{LA EVOLUCIÓN HISTÓRICA DE LA FUNCIÓN JUDICIAL EN EL ORDENAMIENTO JURÍDICO ESPAÑOL}

Podemos tomar como punto de partida en el análisis de la formación histórica de un poder judicial relativamente independiente, el de la Constitución de Cádiz de 1812. La legislación anterior no proporciona al juez ninguna de las notas características de la moderna función judicial.

3 Díz PicAzo ha establecido una clasificación de las sentencias en función de la personalidad de cada juez, que ilustra perfectamente acerca de la influencia de la mentalidad propia del juez en las resoluciones que dicta. Distingue el autor entre sentencias justicieras, que son aquellas en las que el juez antepone el concepto de justicia propio al del ordenamiento. Un ejemplo serían las sentencias absolutorias que algunos jueces dictan en los proceso de objección de conciencia, aplicando a los objetores la eximente de estado de necesidad. Sentencias intimistas, aquellas en las que el juez vuelca aspectos de su vida personal, o de las condiciones materiales de la oficina judicial dentro de las sentencias. Sentencias filosóficas, que difieren de las intimistas en que aquí el juez hace consideraciones sobre la verdad, la justicia, o la igualdad. Sentencias proforma, que consisten en unas plantillas mínimas que se rellenan con los datos de cada caso. Y POR FIN, LO QUE LLAMA Díez Picazo sentencias estrictamente jurídicas, en las que el juez dicta su sentencia ajustándose a los argumentos propiamente jurídicos. L. DiEz-PICAZO. "La justicia y el sistema de fuentes del derecho». AFDUAM. 1997. págs. 205 y ss. 
El art. 242 de la Constitución de Cádiz de 1812, habla de separación de poderes, y los artículos siguientes de inamovilidad, juez legal predeterminado y unidad y exclusividad de la función jurisdiccional ${ }^{4}$.

Hasta la Ley Orgánica del Poder Judicial de 1870, no conocemos en nuestro ordenamiento un perfil de la judicatura con las notas distintivas actuales del juez independiente. Con esta ley y las disposiciones complementarias posteriores, se desarrolla una concepción de una función judicial considerada como ausente de toda valoración y acrítica con toda consideración política, directamente heredera de la tradición francesa del poder judicial como poder neutro, sobradamente estudiada y sobre la que ya no merece la pena detenerse ${ }^{5}$.

Si bien es conveniente señalar que esta función acrítica del poder judicial en Francia, por los recelos a la pérdida de soberanía popular del parlamento, condicionará el futuro del poder judicial hasta hacer inviable históricamente, un esquema de poder judicial sostenido en planteamientos de participación democrática, como es el caso de EE.UU.

$Y$ en segundo lugar, potenciará asimismo un poder institucionalizado y formalizado en órganos de representación y gobierno con poder unitario, que constituya un punto de referencia concreto y real, manteniendo en su lugar la abstracción del poder judicial como un poder puntual que se actualiza en la aplicación del derecho.

La Ley Orgánica del Poder Judicial de 1870, es una Ley Provisional, que fue entrando en vigor paulatinamente. Modificada por la Ley Adicional a la LOPJ de 14 de octubre de 1882.

Lo mas importante de la LOPJ fue que reguló la entrada a la carrera de juez por oposición. Dejó subsistente el 4 turno, nombrando discrecionalmente el gobierno a jueces de la Audiencia y del TS. Este cuarto turno se suprimió en 1902 y la legislación que regule el acceso a la función jurisdiccional se homologará a la de los demás funcionarios con la ley de 22 de julio de 1918, del Estatuto de los Funcionarios de la Administración civil del Estado ${ }^{6}$.

4 Hasta el siglo XIX la justicia todavía se podía encontrar residenciada en el poder real e incluso en algunos particulares.

5 Sobre el Proyecto de Ley de Bases de la Ley Orgánica del Poder Judicial de 1870 y la Ley Adicional y las vicisitudes de los debates parlamentarios, M.A. APARICIO PÉrez. "El status del Poder Judicial en el constitucionalismo español». Universidad de Barcelona. 1995. págs. 95-146.

6 La evolución del derecho judicial en este tramo histórico en Andrés lBAÑEZ- MOVILLA «El poder judicial». Edit. Tecnos. MADRID. 1986. 
Esta situación permanecerá hasta la Constitución de 1931, que con independencia de la situación teórica de la proclamación de la independencia judicial no hizo posible en la práctica esta independencia, de manera que no puede decirse con rigor que durante la Segunda República los jueces fueran totalmente independientes del resto de los poderes del Estado.

En el franquismo, la Ley Orgánica del Estado, proclama la "unidad de poder y coordinación de funciones», que es tanto como reconsiderar dos siglos después la división de poderes, y llamar al poder judicial "función judicial». La ley de 18 de marzo de 1966, del Estatuto Jurídico de los Funcionarios de la Administración de Justicia, constituye la norma de regulación de los jueces durante la última etapa del franquismo ${ }^{7}$.

Hasta la Constitución de 1978 no puede hablarse en puridad de un poder judicial independiente, sino de la función de la Administración de Justicia.

\section{LA FUNCIÓN JUDICIAL EN EL ORDENAMIENTO JURÍDICO ESPAÑOL VIGENTE}

A partir de la publicación de la Constitución, la regulación del poder judicial la encontramos en el título VI que comprende el art. 117 y siguientes de la Constitución que atribuye a los jueces y tribunales la potestad jurisdiccional, juzgando y haciendo ejecutar lo juzgado.

El art. 117 dice que "la justicia emana del pueblo y se administra en nombre del Rey por jueces y Magistrados integrantes del poder judicial, independientes, inamovibles, responsables y sometidos únicamente al imperio de la ley".

La concrección de la inamovibilidad de los jueces se refuerza en el pf. $2^{\circ}$ de éste artículo, cuando se establece que éstos «No podrán ser suspendidos, separados, trasladados ni jubilados, sino por alguna de las causas previstas en la ley".

Y la de la responsabilidad se desarrolla en el art. 121 que constitucionaliza el error judicial y el funcionamiento anormal de la justicia,

7 Corresponde a J. Cano Bueso el estudio mas elaborado desde el punto de vista normativo, de la legislación de la función judicial en el período de Franco. J. CANO Bueso. "La función judicial en el régimen de Franco". Ministerio de Justicia. MADRID. 1985. 
cuándo dice que los daños causados por error judicial y por el funcionamiento anormal en la administración de la justicia, "Darán derecho a una indemnización a cargo del Estado, conforme a la ley".

Respecto de la independencia no se explicita mas en el texto constitucional, pero el art. 122 mandata al legislador a una LOPJ que regule la constitución, funcionamiento y gobierno de los juzgados, y un estatuto único de jueces y tribunales. EI CGPJ es el órgano de gobierno del poder judicial.

$Y$ finalmente, el art. 127 declara las incompatibilidades del juez $y$ su prohibición de militancia sindical y política. La ley completará un cuadro de incompatibilidades que asegurará, dice el pf. 2 del artículo, "la total independencia de los mismos".

El desarrollo legal de estos artículos, se produce por la Ley Orgánica 6/85, de 1 de Julio del Poder Judicial.

Ya la Exposición de Motivos de la LOPJ dice que la indepen. dencia es nota esencial del poder judicial, pero es en el art. 12 donde se reconoce la independencia del juez concretando esta independencia en cuanto a utodos los órganos judiciales y de gobierno del poder judicial"».

Este art. 12 concreta la independencia judicial en dos aspectos: EI relacionado con los recursos, donde el superior no puede corregir al juez inferior sino en virtud de los recursos que la ley establezca, y la prohibición de dictar instrucciones con carácter general dirigidas a sus inferiores.

El art. 13 contiene un mandato general dirigido a que "todos están obligados a respetar la independencia de jueces y magistrados". De tal modo que el art. 14 contiene una reserva de derechos del juez que se considere perturbado o inquietado en su independencia. Lo pondrá en conocimiento del Consejo general del Poder Judicial dando cuenta de los hechos al juez competente en el procedimiento, y practicando él mismo las diligencias estrictamente indispensables para asegurar la acción de la justicia y restaurar el orden jurídico. El pf. segundo del art. 14 otorga competencias al Ministerio Fiscal para asegurar la independencia judicial.

Este cuadro expuesto contiene la normativa legal por la que actualmente se conduce la independencia en la función judicial.

$Y$ tanto en la formulación constitucional como en el desarrollo legal, se han producido importantes modificaciones del status del juez en su formulación actual. 


\section{a) La aplicación del derecho y el sistema de fuentes}

La innovación que ha supuesto la Constitución en el desempeño de la función judicial respecto del sistema de fuentes, debe buscarse en todos los preceptos constitucionales, pero hay algunos de ellos que innovan y atañen de manera muy directa al desempeño de la función judicial. En primer lugar, el art. 9,2 de la Constitución, que obliga al juez a remover los obstáculos para que el cumplimiento de la igualdad y la libertad sean reales $y$ efectivos.

En segundo lugar y seguramente como el precepto más importante relacionado con la actividad del juez, el art. 24 de la Constitución que establece la necesidad de motivar las resoluciones judiciales. La motivación de las resoluciones judiciales entraña como se ha dicho, dar satisfacción a la seguridad jurídica, conocer los argumentos para la formulación de los oportunos recursos, y facilitar el control social del derecho ${ }^{8}$.

Ahora bien, en general el sistema de fuentes que se genera en nuestro ordenamiento a partir de la vigencia de la Constitución, tiene consecuencias de alcance para la actividad de la aplicación del derecho por parte de los jueces.

Hemos visto como, pese a la redacción del art. 117 de la Constitución, que establece que la justicia se administra por jueces sometidos únicamente al imperio de la ley, la Constitución ha supuesto una innovación importante en el sistema de fuentes, no sólo por el vigor de la misma Constitución como fuente ${ }^{9}$, que implica la referencia en el plano interpretativo a valores y principios constitucionales que reducen las posibilidades interpretativas del derecho a las que proporciona la Constitución misma, sino por la ampliación, en virtud de los mismos preceptos constitucionales, del sistema de fuentes en lo que se ha llamado un pluralismo ordinamental inexistente antes de la Constitución. Después de la Constitución y como consecuencia de ella, de ha producido la existencia de una importante proliferación de los órganos de producción normativa. De una parte con la división territorial del Estado, que en el art. 147.1 se consideran como "norma institucional básica» de cada Comunidad Autónoma, y cuyo reconocimiento por parte del Estado es constitucionalmente obliga-

8 M.L. Balaguer "La interpretación de la Constitución por la jurisdicción ordinaria». Civitas. MADRID. 1990. pág. 128.

9 Sobre la relación entre la Constitución y el sistema de fuentes en su dimensión axiológica, y en referencia al modelo de Estado y de Gobierno, F. BaLAguer "Fuentes del derecho". T. I. pág. 59. 
do, "como parte integrante del ordenamiento jurídico". Los arts. 148 al 150, regulan la distribución de competencias entre las CC.AA. y el Estado, en orden a la producción normativa de ambos, según unos criterios, constitucionalmente establecidos para el ejercicio de la potestad legislativa en el Estado y en las Comunidades Autónomas.

Por su parte el art. 96.1 de la Constitución, incorpora al ordenamiento jurídico estatal, los tratados internacionales válidamente celebrados, y una vez publicados oficialmente en España.

Por tanto, el sistema de las fuentes del derecho se trastoca desde la Constitución, proporcionando una diferente jerarquización de las normas, con sujeción a los valores de la Constitución, y una ampliación de los órganos de producción del derecho, que en el caso del derecho comunitario, desborda los órganos estatales de producción.

\section{b) La actividad interpretativa del juez en la aplicación del derecho}

Lo que caracteriza a la función judicial es la aplicación de una norma a un caso, interpretada conforme al ordenamiento jurídico.

Ello implica que el juez ha de realizar una actividad, la de interpretación de la norma, ver si es pertinente al caso, y aplicarla. La interpretación difiere en este caso de la aplicación en que es un paso previo a ésta. Se aplica la norma una vez que se ha detectado que esa norma es pertinente a la solución del caso. Podemos decir que la interpretación es una fase previa de determinación, y la aplicación es la fase de adecuación. La actividad intelectual que despliega el juez desde el planteamiento del problema hasta la solución, constituye el camino hermeneútico sujeto a un método. $Y$ es precisamente en el campo de la metodología jurídica donde se encuentran hoy la mayor parte de las cuestiones relacionadas con función jurisdiccional. En la medida en que es aquí donde se residencian la mayor parte de los problemas que afectan a la función constitucional del juez ${ }^{10}$.

10 M.L. BaLAgUeR «Interpretación de la Constitución y ordenamiento jurídicon. Edit. Tecnos. MADRID. 1997. Pág. 38. Es precisamente en el campo de la interpretación donde se produce un importante desplazamiento de los problemas teóricos que planteaban la legitimación del poder judicial, y su eventual déficit democrático. Cuándo se plantea la legitimidad del poder judicial desde la exigencia de la representación, se ignora que junto a las instituciones representativas, son necesarias las instituciones de control del poder. En tal sentido, la legitimidad dei poder deriva de su sumisión al ordenamiento. lb. Pág. 51. 
Naturalmente la actividad interpretativa tiene unos límites que si el juez rebasa, se sitúa en el decisionismo judicial, o en el arbitrismo.

Cuando se dice que la actividad interpretativa del juez ha de someterse al sistema de fuentes establecido, se está considerando que el sistema de fuentes es claro, que el caso sometido a conocimiento es razonablemente abordable conforme a las normas del ordenamiento, $y$ que existen decisiones judiciales anteriores capaces de contribuir a solventar la que en ese momento se presenta. A veces alguna de estas situaciones no concurre, y por ello nos encontramos ante situaciones en las que el ordenamiento jurídico no responde a las exigencias de justicia que las partes demandan.

\section{Esto puede ocurrir por diferentes causas:}

1. Lo que se ha llamado por algunos autores "casos difíciles", o "casos trágicos»" ${ }^{11}$. Estos casos pueden ocurrir por la naturaleza del caso enjuiciado, por la dificultad de la regulación de ese supuesto, o por la complejidad del cuadro normativo a aplicar ${ }^{12}$.

2. Situaciones en que las normas de aplicación son genéricas o abiertas. En estos casos de apertura de las normas, el juez puede elegir entre varios criterios de interpretación: acudir al legislador histórico, actualizar la visión del legislador, resolver conforme a sus valores, o acudir al sistema social de valores..$^{13}$ Cada una de estas opciones se corresponde con una visión distinta del derecho, y encierra a su vez un modelo de función judicial, pero todas sin excepción representan una visión creadora de las normas jurídicas. A veces son normas suceptibles de diversas interpretaciones por la propia naturaleza de su objeto, como en el caso de la responsabilidad extracontractual por daños del art. 1902 de nuestro Código Civil. El desarrollo de una extensa jurisprudencia en torno a un precepto comprensivo de situaciones tan dis-

11 Llama Dworkin casos difíciles a aquellos en los que el juez tiene dificultad de encontrar la norma de aplicación, bien porque la regulación sea defectuosa, o bien porque el caso presenta dificultades intrínsecas en su aplicación por problemas morales. R. Dworkin.- "Los derechos en serio". Ariel. BARCELONA. 1984.

12 M. Atienza "Tras la justicia". Ariel. BARCELONA. 1993. pág. 149. Considera casos difíciles aquellos en los que o bien no existe norma, o esta causa problemas en su interpretación, o no están claramente probados los hechos o su calificación jurídica resulta controvertida.

13 Para AARNIO, la actividad interpretativa atiende a dos directrices: las fuentes $y$ el procedimiento del discurso. Las fuentes hacen que la interpretación sea jurídica, y el procedimiento del discurso, que la decisión esté justificada. L. AARNIO «Lo racional como razonable». CEC. MADRID. 1991. pág. 182. 
pares, exige una actividad creativa del juez por encima de lo que se puede considerar una actividad jurisdiccional sometida a la ley.

Incluso en aquellos supuestos en los que la norma parece paladinamente clara, es necesaria una actividad jurisdiccional tendente a dar cuenta de su claridad ${ }^{14}$.

3. Remisión de la propia norma a la actividad creativa del juez. A veces la propia norma mandata al juez para que decida el marco en el que se ha de producir su decisión. El caso de la claúsula contractual de "rebus sic stantibus", que permite al juez decidir la validez de una ruptura contractual cuando las circunstancias hayan cambiado sustancialmente. La valoración del cambio en las circunstancias corresponde al juez. O la oportunidad de la crisis económica de las empresas que aconseje la reducción de los puestos de trabajo, o la revisión jurisdiccional de una incapacidad resuelta por una comisión médica.

También es importante considerar la actividad del juez en algunos procedimientos de jurisdicción voluntaria, o en los procesos concursales en los que mantiene una actitud mas arbitral que jurisdiccional, de vigilancia de los interventores o síndicos, que liquidan o gestionan el patrimonio de la mercantil.

Como quiera que cualquier teoría de la interpretación, ha de moverse dentro de los límites que la Constitución tiene establecidos, la interpretación que el juez efectúe de la ley, tiene como límite la Constitución, dado que en ella se contienen el conjunto de valores y derechos que el constituyente ha considerado en el pacto social.

La Constitución normativa, contra lo que pudiera parecer, restringe la actividad interpretativa del juez, en tanto en cuanto pone lími-

14 Respecto del axioma "in claris non fit interpretation, y su consecuencia mas directa, la posibilidad de una sola solución correcta en el derecho, hay posiciones doctrinales de autores no tan recientes, que han cuestionado la virtualidad de un contenido claro en el derecho que exima de la función interpretativa. J. EsSER ve en la detección de la claridad una actividad interpretativa clara que exige un esfuerzo menor, pero relativamente intenso de indagación. J. ESSER «Principios y normas en la elaboración del derecho privado". BARCELONA. 1984. Pág. 323. También para Betti, que ve en la claridad un concepto a posteriori de la interpretación, considerado como el resultado de un proceso interpretativo, y no como la sola lectura del precepto. E. Betti.- "La interpretación de las leyes y de los actos jurídicos". Revista de derecho privado. MADRID. 1975. Pág. 250. Finalmente Larenz, para quién el propio sentido gramatical de las expresiones, no tiene ni mucho menos un sentido unívoco. K. LARENZ "Metodología de la ciencia del derecho". Edit. Ariel. BARCELONA. 1960. Pág. 254. 
tes a la actividad jurisdiccional. A simple vista parecería que un ordenamiento jurídico en el que la Constitución fuera programática, y el juez resolviera conforme a la ley, constreñiría la actividad jurisdiccional al texto legal, y el juez que al resolver en derecho ha de conformar la ley a la Constitución, tendría un campo más amplio de principios y valores a los que atener su resolución judicial. Como ha puesto de manifiesto Viehweg, es justo al contrario, la existencia de una Constitución normativa, restringe las posibilidades del juez a aquellos valores y principios que estén contenidos en la Constitución, y suponen un límite a la actividad interpretativa del juez. ${ }^{15}$

Entre el mínimo y el máximo, hay zonas de certeza y zonas de penumbra. El TC ha definido las zonas de certeza, como aquellos mínimos indisponibles ${ }^{16}$ para el legislador, pero ha dejado abiertas las zonas de penumbra, en las que la interpositio legislatoris tiene la posibilidad de restringir o ampliar los contenidos de ciertos derechos.

En este punto se plantea la libertad de creación del derecho por parte del juez. Entre un mínimo que lo constituye la exigencia constitucional, y un máximo que lo constituye el límite de la Constitución. En ese margen, el juez puede dictar una resolución, que cumpliendo las exigencias de motivación del art. 120 de la Constitución, satisfaga las exigencias del ordenamiento. La Constitución abierta, que Häberle plantea como posibilidad de un permanente diálogo social entre los intérpretes está en el fundamento mismo de ese pluralismo metodológico por el que el juez resuelve conforme a los valores propuestos por la Constitución, en un diálogo con abierto entre el juez y la sociedad. ${ }^{17}$

El margen de creación del juez en relación con las normas constitucionales, difiere en función del grado de aplicabilidad de las diferentes normas constitucionales. Cuando el juez efectúa una aplicación judicial de normas constitucionales directamente aplicables, sus parámetros vienen determinados por la exigencia constitucional. Su interpretación queda constreñida por el texto constitucional. Cuando hay una ley aplicable, además de un derecho fundamental reconocido, el juez además de respetar la Constitución, ha de respetar los parámetros legales. De este modo, la ley a su vez puede restringir el derecho en mayor o menor grado de lo que lo haga la Constitución.

15 T. VIEHWEG «La filosofía del derecho como investigación básica». En "Tópica y filosofía del derecho». Edit. Gedisa. BARCELONA. 1992. pág. 44.

16 1996.

17 P. HÄberLe «Retos actuales del Estado Constitucional». IVAP: OÑATI. 


\section{c) La relación del juez con otros órganos constitucionales y jurisdiccionales}

Hasta aquí hemos definido un criterio de ordenación de la actividad jurisdiccional mas o menos estático, que se corresponde con las posibilidades previamente marcadas en las normas en relación con su rango. Me gustaría ahora abordar el problema desde un punto de vista dinámico, de las previsiones que adopta el ordenamiento respecto del comportamiento del juez cuando ha de resolver el caso concreto que se le somete a enjuiciamiento.

Para ello el juez ha de observar las siguientes normas:

- El concepto de interpretación conforme. Conformidad que deviene de la exigencia del art. 163 de la Constitución, del art. 35 de la LOTC y del art. 5.2 de la Ley Orgánica 6/85, de 1 de Julio del Poder Judicial.

Cuando se dice que el juez ha de interpretar todas las normas de acuerdo con la Constitución, o de conformidad con la Constitución, se entiende que la Constitución ha devenido parámetro de interpretación. Ello implica que lo que antes de la Constitución eran los principios o los valores, como criterios interpretativos, ahora es la Constitución misma. Pero decir que la Constitución es un parámetro de validez de las normas, implica considerar, desde el punto de vista dinámico, que el juez ha de basar su decisión en los valores y principios constitucionales. A los principios y valores del ordenamiento jurídico en general, que presidian la actuación judicial preconstitucional, sucede ahora una interpretación basada en la Constitución. Lo que desde el punto de vista práctico reviste cierta importancia, pues a menudo el juez ha de desenvolver su actividad interpretativa basándose en principios contradictorios. El principio acusatorio contra el principio inquisitorial, la carga de la prueba, los criterios de interpretación extensiva o restrictiva. Si estamos en clave de interpretación conforme, tendremos que interpretar la norma de forma extensiva para los Derechos Fundamentales, restrictiva en el ámbito del derecho punitivo, repartir la carga de la prueba. Esto es exactamente lo que implica la «interpretación conforme" desde el punto de vista de las normas sobre interpretación. Cuándo un juez interpreta las normas conforme a estos criterios interpretativos, estamos ante una interpretación conforme, la Constitución se ha convertido en parámetro de constitucionalidad.

- La aceptación de la jurisprudencia del TC como fuente de derecho. Es cierto que la redacción del art. 123 de la Constitución establece la superioridad del TS en todos los órganos jurisdiccionales del territorio español, pero la excepción respecto del Tribunal Constitucional en 
materia de garantías constitucionales, ha creado puntos de fricción importantes respecto del alcance real de la superioridad del Tribunal Supremo, que se acentúan si tenemos en cuenta los mecanismos instalados en el ordenamiento a partir de la LOTC que permiten obtener diferente conclusión a este respecto.

Estos mecanismos son:

a) En materia de inconstitucionalidad de las leyes:

El art. 38 de la LOTC, recogiendo el art. 161.1 de la Constitución, y el artículo 164, fija el valor de cosa juzgada de las sentencias del Tribunal Constitucional recaídas en los procedimientos de inconstitucionalidad ${ }^{18}$.

El art. 40, 2 de la LOTC amplía la disciplina jurisprudencial del art. $161,1, a$, a los autos dictados por el TC, lo que sin duda agrega una importancia trascendental en aquellos procesos desestimatorios de la inconstitucionalidad, que el TC no lleva a sentencia y rechaza por ser manifiestamente improcedente el planteamiento de una cuestión de inconstitucionalidad. Pero lo mas importante de la aportación del art. 40 de la LOTC en cuanto a la relación entre la jurisdicción ordinaria y constitucional, es sin duda la competencia que se atribuye al TC en cuanto a la unidad material del ordenamiento.

El efecto corrector de la jurisprudencia de los utribunales de justicia", que atribuye la Ley al TC en el dictado de sentencias $y$ autos, determina la sumisión de todos los jueces y tribunales, con inclusión del propio TC tanto cuándo actúa en Sala como cuándo lo hace en Pleno, (en la medida en que él mismo viene obligado también a respetar sus propios criterios interpretativos cuándo actúa en Sala por la exigencia del art. 13 de la LOTC de someterse al Pleno si considera necesario apartarse en cualquier punto de la doctrina constitucional precedente, y cuándo actúa en Pleno por las propias exigencias contenidas en el art. 24 de la Constitución respecto de la necesidad de motivar el cambio de orientación en las resoluciones judiciales).

b) Por lo que respecta a los recursos de amparo, dos son los datos que nos llevan al mismo razonamiento: El propio artículo 123 que salva de la superioridad jerárquica del Tribunal Supremo, "lo dispuesto en materia

${ }_{18}$ El efecto de cosa juzgada viene ya reconocido en el art. 164 de la Constitución que reafirma la obligatoriedad del art. 161,1, a en los efectos correctores de la jurisprudencia de los tribunales, extendiendo erga omnes los efectos de las sentencias dictadas en procesos de inconstitucionalidad, que quedan así establecidos no sólo frente a los jueces y tribunales, sino con valor de normas jurídicas aplicables por todos los aplicadores jurídicos. 
de garantías constitucionales", lo que en la práctica ha convertido al TC en la última instancia de juicio acerca de los Derechos Fundamentales. $Y$ además el art. 5.1 de la LOPJ que obliga a los jueces y tribunales a interpretar las leyes y reglamentos "conforme a la interpretación de los mismos que resulte de las resoluciones dictadas por el Tribunal Constitucional en todo tipo de procesos». Contrariamente a lo que se ha dicho por algunos autores respecto de la inutilidad de este artículo por reiterativo de otros, es importante analizar las dos ampliaciones que contiene respecto de la Constitución y de la LOTC en estos dos aspectos:

Ampliación a "todo tipo de procesos" de los criterios interpretativos que antes de la LOPJ regian solamente para los procesos de inconstitucionalidad.

Ampliación a los reglamentos de los criterios interpretativos que antes regían solamente para las normas con rango de ley ${ }^{19}$.

Por lo tanto el juez tiene determinadas por el ordenamiento las siguientes limitaciones:

1. El texto que sirve de soporte a la norma. Cualquier interpretación ha de tener en cuenta que la norma tiene un sentido y el intérprete ha de indagar el sentido de la norma. Aunque solo sea para dar cuenta de su incongruencia, el intérprete ha de partir del texto dado. $Y$ si la interpretación textual es conforme a la constitución, pese a que su sentido sea forzado, y pese a que la letra sea contraria al espíritu de la Constitución, ha de prevalecer el texto ${ }^{20}$.

2. El autocontrol de la actividad del juez, que viene obligado a permanecer "intralege" e "intraconstitutione». Este mecanismo adquiere importancia en aquellas normas de delegación, o justificadas por la urgencia, en las que el control de la oportunidad se sustrae al conocimiento jurisdiccional.

Para que el juez en su actividad de aplicación de las normas, quede efectivamente "intraconstitucione», no sólo ha de interpretar

19 Respecto del control reglamentario en su control de constitucionalidad, F. BalAguer "Aplicación de la Constitución y Garantía de los derechos». Anuario de

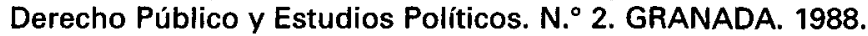

20 St. 108/86, del TC por la que se consideran sin relevancia constitucional los debates parlamentarios en la redacción del art. 122,3 de la Constitución en lo atinente al sistema de designación de los vocales del CGPJ. Ni el espíritu ni la finalidad pretendidos en cuánto a asegurar el pluralismo ideológico, pese a que esta redacción haga correr el peligro de que se frustren, son suficientes para enervar la letra del texto. 
conforme el propio juez considere que el sentido que confiere a la norma es acorde con "su» interpretación de la Constitución, sino que ha de plegar su conformidad a los criterios interpretativos que el Tribunal Constitucional considere "conformes" a la Constitución. Su interpretación de la Constitución no es libre, sino reglada por las pautas interpretativas que viene creando el $\mathrm{TC}^{21}$. Es muy importante comprender desde esta realidad, la necesidad de crear unas reglas hermeneúticas precisas acerca de la interpretación. Lo que se puede llamar normas sobre interpretación, (NSI) es un concepto que pretende sistematizar los criterios jurisprudenciales dictados por el TC en sus resoluciones, y crear un cuerpo de doctrina sometidos al rigor y la precisión jurídicas.

Ello implica que las correcciones que el TC efectua en los procesos de aplicación de las normas, constituyen normas jurídicas de aplicación a futuros supuestos ${ }^{22}$.

21 Es interesante a este respecto tener en cuenta la Sentencia que el TC dicta en la resolución de un recurso de amparo, (110/88) acerca de la inconstitucionalidad del art. 240 de la LOPJ. Se estima el amparo con ocasión de la aplicación incorrecta del art. 240, por la que el juez no accede a la nulidad de actuaciones y su reposición al momento de una citación incorrecta. La sentencia que da término a la autocuestión planteada con ocasión del amparo frente a lees, St. 185/90, desestima la autocuestión y el Pleno del TC sin contradecir a la Sala, considera que el amparo se concede precisamente por la interpretación errónea del juez del art. 240 de la LOPJ, en relación con el concepto de sentencia definitiva, que debe entenderse como «la sentencia definitivamente ejecutada". La contradicción aparente entre un amparo estimatorio $y$ una autocuestión desestimatoria, exige un esfuerzo de comprensión de cuales son los límites en la actividad del TC en orden a la creación de criterios interpretativos. En este caso concreto, el principio de conservación de las normas, ha llevado al TC a forzar un sentido interpretativo del art. 240 de la LOPJ seguramente ajeno a la mente del legislador cuando considera que en una sentencia firme, el juez no dispone de jurisdicción para anular las actuaciones. Pero la tutela judicial efectiva que se satisface con la citación a juicio, junto a la necesidad de mantener en la medida de lo posible la constitucionalidad de las leyes, lleva al Tribunal Constitucional a salvar la constitucionalidad del precepto. Tanto en la sentencia en la que otorga el amparo como en la desestimatoria de la autocuestión, la interpretación que ofrece, establece un estrecho margen al juez, obligado a partir de ese momento a interpretar el concepto de sentencia definitiva como diferente de sentencia definitivamente ejecutada.

22 Las normas que el TC cuándo interpreta la Constitución, han sido llamadas por E. Alonso normas subconstitucionales, por F. Balaguer normas paraconstitucionales, y lo que aquí se postula es el concepto de normas sobre interpretación, que difiere de las anteriores denominaciones en que no abarca solamente a las normas de la constitución, sino en general al conjunto de reglas y normas sobre interpretación. E. Alonso García.- "La interpretación de la Constitución". CEC. MADRID. 1984. F. BALAGUER "Tribunal Constitucional, poder legislativo y poder constituyente». Rev. Jurídica Castilla-La Mancha. N. 3 y 4.1988. 
Esta tesis tropieza con una objección importante respecto de la naturaleza y funciones de la jurisdicción constitucional. La Constitución ha atribuido al TC competencias reducidas al control de constitucionalidad, amparo de ciertos derechos, y conflictos de competencias. Por ello, la interpretación de las normas que no revistan relieve constitucional, queda residenciado en la jurisdicción ordinaria, sin que quepa en principio, ningún pronunciamiento del TC al respecto.

Por ello, las normas sobre interpretación quedan en este plano reducidas a los aspectos constitucionales de las normas. Circunstancia muy compleja de determinar porque implica un concepto de constitución relativamente desgajado del resto del ordenamiento, en la medida en que todo lo que no revista importancia constitucional, es ajeno al TC, lo que viene a significar la posibilidad de dos mundos jurídicos nuevamente divididos, el constitucional y el ordinario, como podría ser el legal y el reglamentario. Pero la aplicación de las normas no se sostiene en esos compartimentos argumentales, que momentizan en su actividad interpretativa la ley o la Constitución, sino que la resolución de un conflicto jurídico conlleva normalmente la consideración de un número indeterminado de normas, de diferente rango, que de forma armonizada coadyuvan a la solución del conflicto mediante la resolución judicial. La selección del campo normativo preciso, requiere que el juez indague acerca de las que han de seleccionarse como pertinentes al caso, y además que aplique conforme al sistema de fuentes, según los principios de jerarquía y competencia. Por ello, puede decirse que en todos los procedimientos judiciales son potencialmente de aplicación las normas constitucionales, en realidad son potencialmente aplicables todas las normas, si bien el juez aplicará aquellas del conjunto del ordenamiento que sean idóneas o pertinentes para la solución del caso.

El comportamiento, por otra parte respetuoso, del TC en un meritorio ejercicio del "self-restraint", representa un obstáculo serio a la conformación de este cuerpo doctrinal en materia interpretativa. Precisamente en la selección del derecho aplicable el TC ha reafirmado la competencia de la jurisdicción ordinaria ${ }^{23}$.

23 La St. 109/88 del TC considera competencia de la jurisdicción ordinaria la selección de las normas de aplicación, y su interpretación, con el único límite de que esta interpretación cumpla las exigencias de ser conforme con la Constitución. Igual la 166/94, y mas recientemente la St. 176/95, que considera actividad de la jurisdicción ordinaria tanto la selección como la interpretación, la libre valoración de la prueba, la fijación de los hechos en el proceso, y la posibilidad de hacer ejecutar lo juzgado. En cuanto a la denegación de pruebas, ciertamente exige el TC que cuando un juez deniegue una prueba, razone las causas de su denegación, (St. 131/95). 
Pero al TC no se le oculta la unidad del ordenamiento a que nos hemos referido hace un momento. El ordenamiento no puede ser doble, ordinario y constitucional, sino que el ordenamiento exige unidad, y por ello, recientemente parece orientarse en esa posición superadora de un dualismo funcional celoso de la independencia judicial pero de discutible resultado práctico ${ }^{24}$.

Por lo tanto, la elaboración de unas normas sobre interpretación, tienen que construirse con las limitaciones que en materia de competencias tiene señaladas el TC por la misma constitución, y por su propio desarrollo jurisprudencial.

Con todo, el desarrollo de las normas sobre interpretación, implica un importante esfuerzo sistemático. Es necesario conocer de forma sistemática y ordenada los criterios interpretativos del TC desde la detección de la norma aplicable hasta su adecuada interpretación, desde la conformidad constitucional.

\section{CONCLUSIONES}

PRIMERA.- Respecto de la novedad que supone la Constitución en la consideración de la actividad jurisdiccional como una actividad independiente, sometida solamente al derecho y con los rasgos distintivos del poder judicial, se han dejado entrever ciertas insuficiencias que dejan en evidencia un poder judicial a veces puramente nominalista. Desde nuestro punto ello permite obtener algunas conclusiones:

La proliferación de los jueces estrella y las situaciones creadas en la judicatura respecto de la judicialización, a veces trivial, de algunos aspectos sobresalientes en política, que convierten a la justicia en un campo de batalla política.

Se trata de una situación que no sería pensable desde un poder judicial centralizado, en el que, salvando la independencia de la función jurisdiccional propiamente dicha, el Consejo mantuviera un núcleo referenciado de poder, similar al resto de los poderes del Estado. Es precisamente la ausencia de este poder, la que concede al juez, el protagonismo que debería tener el Consejo.

24 En la St. 179/94, el TC Ilama la atención acerca de la necesidad de interpretar el ordenamiento desde el principio de la unidad del ordenamiento constitucionalmente reconocida. También en la 102/95. 
Poder implica capacidad financiera de autogestión administrativa. La forma de realizar el poder y su democratización a los efectos territoriales, o sea la articulación de los niveles autonómicos y provinciales, podría abordarse con criterios burocráticos integrados en la Administración del Estado, pero un ejercicio del poder judicial como poder, implicaría la eliminación de algunas de las instituciones de la Administración del Estado que centralizan todavía la Administración de justicia. La articulación en el supuesto de la eliminación de estas funciones, se podría establecer, mediante instancias de colaboración a través de un Secretario de relaciones parecido al de relaciones con las Cortes.

La función de autogobierno y la autonomía presupuestaria, son inherentes a la consideración del poder judicial como un poder del Estado.

SEGUNDA.- Respecto de la función judicial en el plano interpretativo, el desarrollo sistemático de una metodología que supere los aspectos formales de la interpretación. Ello conlleva volver a plantearse la afirmación de algunas cuestiones consideradas hasta hace poco como indiscutidas: Unidad del método interpretativo, por pluralismo metodológico al servicio de la efectividad de la interpretación. La pluralidad de los métodos interpretativos, entendidos estos como la pluralidad de técnicas de interpretación al servicio de la determinación del sentido de la norma, no solo es funcional, sino que aumenta las posibilidades de la argumentación jurídica, en cuanto que amplía las posibilidades de solución al caso. Al mismo tiempo el pluralismo metodológico favorece una ontología del derecho de base plural. Son indeterminadas las posibilidades interpretativas, en la medida en que son indeterminadas las cuestiones que afectan al concepto mismo de derecho o de Constitución. Puesta en cuestión de axiomas clásicos, como el axioma de in claris non fit interpretatio.

TERCERA.- La adopción de una disciplina en materia interpretativa de las normas, que acepte la supremacia interpretativa del Tribunal Constitucional, no solamente en materia de constitucionalidad, sino en la totalidad del ordenamiento jurídico. Ello supone una redefinición de las relaciones entre los diferentes órganos jurisdiccionales en relación con el Tribunal Constitucional, si bien competencialmente limitada en la materia. Limitación en la competencia, pero no limitación en la interpretación de la Constitución. El límite a la actividad interpretativa del TC es la Constitución misma.

Desde la creación de un cuerpo consistente de «normas de interpretación", la actividad del juez se desenvuelve en unos márgenes de orientación que, a la vez que proporcionarian un núcleo importante de 
conceptos básicos de interpretación en materia constitucional, constituyen asimismo una importante limitación de la arbitrariedad o el decisionismo judicial.

Para aceptar la consideración de que las normas que el TC crea en la interpretación de la Constitución, son normas sobre interpretación que deben aceptar los jueces en su actividad jurisdiccional, es necesario que se acepte previamente que la aplicación del derecho supera la labor exegética. Redefinir el dogma como el derecho dado, el dogma es el dato textual, el texto que nos viene dado en el derecho. No se puede contradecir el texto, pero este es a la vez el único límite a la interpretación: el texto. Fuera del respeto al texto, las lecturas, las interpretaciones que se pueden ofrecer del texto, son si no infinitas, al menos indeterminadas. $Y$ la determinación la lleva a cabo el TC, y por ello, una vez determinado un sentido de los posibles, el juez ha de acatar ese sentido, porque es el que disciplina el TC. Hay en todo caso una sola excepción, la de aquellas otras interpretaciones del juez que no contradigan esa y que puedan favorecer la expansión de un Derecho Fundamental, habida cuenta que el ordenamiento jurídico no admite el contraamparo. Ciertamente los excesos en la aplicación de un excesivo amparo en materia de Derechos Fundamentales por parte del juez, no tiene corrección posible por parte del TC a menos que de ello resulte la lesión de otro Derecho Fundamental. (Teoría de la ponderación de los Derechos Fundamentales).

CUARTA.- Finalmente, la aceptación por parte de los jueces y tribunales ordinarios, de una disciplina interpretativa por parte del TC, lo que llamamos normas sobre interpretación, (NSI), exige un adecuado "self-restraint" por parte del TC del que seguramente la sentencia $7 / 94$ no es el mejor ejemplo.

Para que se produzca la aceptación de esa autoridad, que tiene un respaldo constitucional en el art. $161,1, a)$ y un respaldo legal en el art. 40 de la LOTC y 5.1 de la LOPJ, es necesario que el juez no se sienta afectado en su independencia. Y para ello han de mantenerse los límites que la Constitución atribuye a la jurisdicción ordinaria en relación con la jurisdicción constitucional, en la función de juzgar y hacer ejecutar lo juzgado, en tanto que el TC solamente ha de declarar la constitucionalidad e inconstitucionalidad de las normas.

\section{BIBLIOGRAFÍA}

AAIRNIO, A.: "Lo racional como razonable». CEC. MADRID. 1991.

Alonso García, E.: "La interpretación de la Constitución». CEC. MADRID. 1984. Andrés, P. y Movilla Álvarez, C.: “ El poder judicial». Tecnos. MADRID. 1986. 
Aparicio Pérez, M.A.: “El status del poder judicial en el constitucionalismo español». Universidad de Barcelona. BARCELONA. 1995.

AtIEnZA, M.: "Tras la justicia». Edit. Ariel. BARCELONA. 1993.

Balaguer Callejón, F.: "Aplicación de la Constitución y garantía de los derechos". Anuario de Derecho Público y estudios políticos". N. 2. GRANADA. 1988.

Balaguer Callejón, F.: "Tribunal Constitucional, poder legislativo y poder constituyente". Revista Jurídica Castilla-La Mancha. N. 3 y 4. 1988.

Balaguer Callejón, F.: "Fuentes del derecho». Edit. Tecnos. MADRID. 1990. Vol. I y II.

Balaguer Callejón, M.L.: «La interpretación de la Constitución por la jurisdicción ordinaria». Edit. Civitas. MADRID. 1990.

Balaguer Callejón, M.L.: «Interpretación de la Constitución y ordenamiento jurídico". Edit. Tecnos. MADRID. 1997.

BETTI, E.: "Interpretación de la ley y de los actos jurídicos". Revista de Derecho Privado. MADRID. 1975.

Cano Bueso, J.: "La política judicial del régimen de Franco". Ministerio de Justicia. MADRID. 1985.

Diez PICAZO, L.: "La justicia y el sistema de fuentes del derecho". AFDUAM. MADRID. 1997.

DWorkin, R.: "Los derechos en serio». Ariel. BARCELONA. 1984.

ESSER, J.: «Principios y normas en la elaboración jurisprudencial del derecho privado". Edit. Bosch. BARCELONA. 1961.

GeRPE, M.: "La división de poderes: el poder judicial». Edit. A. Monreal. BARCELONA. 1997.

HÄBerLe, P.: «Retos actuales del Estado Constitucional». IVAP. OÑATI. 1996.

LARENZ, K.: "Metodología de la ciencia del derecho». Edit. Ariel. BARCELONA. 1966.

OTto PARDo, I. De.: "Estudios sobre el poder judicial». Ministerio de justicia. MADRID. 1989.

Pérez Tremps, P.: "Tribunal Constitucional y poder judicial». CEC. MADRID. 1985.

VV.AA.: "Los procesos constitucionales". CEC. MADRID. 1992.

VV.AA.: "La jurisdicción constitucional en España". CEC. MADRID. 1995.

VV.AA.: "Jurisdicción y procesos constitucionales". Colección Ciencias Jurídicas. MADRID. 1997.

VV.AA.: "La aplicación jurisdiccional de la Constitución». Tirant lo Blanch. VALENCIA. 1997.

VIEHWEG, T.: "Tópica y filosofía del derecho». Edit. Gedisa. BARCELONA. 1992. 